\title{
Gel-Permeation Effect on Compositional Fractionation of Copoly(styrene/methyl acrylate) by High Performance Liquid Chromatography
}

\author{
Shinya Teramachi, Akira Hasegawa, Yuji ShigeKuni, \\ and Shinji MATUNAGA \\ Department of Industrial Chemistry, Kogakuin University, \\ Nakano-cho 2665-1, Hachioji, Tokyo 192, Japan
}

(Received March 1, 1989)

\begin{abstract}
The effect of gel-permeation on the compositional fractionation of copoly(styrene/methyl acrylate) by high performance liquid chromatography (HPLC) was studied. Mixtures of copolymer samples with different chemical compositions were fractionated by normal-phase HPLC using two columns of $\mathrm{CN}$-modified silica gels with different micropores (nominal values: 10 and $30 \mathrm{~nm}$ ) and the gradient elution of a mixture of tetrahydrofuran and cyclohexane. The samples were clearly separated into the original components according to chemical compositions by the column of $10 \mathrm{~nm}$, while the separation by the column of $30 \mathrm{~nm}$ was very poor. The respective peaks were very low and had very long tails in the latter case. Especially, a sample of low molecular weight could not be detected. Moreover, in the chromatograms of the samples with the same chemical composition but different molecular weights by the column of $10 \mathrm{~nm}$, the peak area of a sample with a molecular weight lower than $10^{5}$ was half those of other samples with higher molecular weights than $10^{5}$. These findings may imply that the gel-permeation effect is unfavorable to compositional fractionation, when the micropores are so large that large amounts of the copolymer samples can permeate into the micropores.

KEY WORDS Copoly(styrene/methyl acrylate) / Compositional Fractionation / HPLC / Normal-Phase Adsorption / Gel-Permeation Effect /
\end{abstract}

In the molecular characterization of copolymers, it is important to determine chemical composition distribution (CCD). Recently, high performance liquid chromatography (HPLC) has been used for determining CCD of copolymers based on both the mechanisms of adsorption-desorption and phase-separation. The former mechanism, which has been applied widely to characterization of polymers in thin layer chromatography, ${ }^{1}$ was introduced into HPLC of copolymer by us in $1979 .^{2}$ The latter mechanism, which has been used in bach or preparative column, ${ }^{3}$ was introduced into HPLC as HP-precipitation-LC by Glöckner et al. in $1982 .{ }^{4}$ Since then, both mechanisms have been used together or separately for compositional fractionation of copolymers by several authors. ${ }^{5-22}$

On the other hand, gel-permeation chromatography has been used widely to determine molecular weight distribution. However, the gel-permeation mechanism may disturb compositional fraction of copolymers, as pointed out by Glöckner et al., ${ }^{9}$ if the mechanism coexists with mechanisms of adsorptiondesorption and/or phase-separation.

It is the purpose of the present work to show the results of compositional fractionation of stat-copoly(styrene/methyl acrylate), (SMA) by HPLC using two columns with different micropore sizes and discuss the effects of these mechanisms on the compositional fractionation of the copolymer. 


\section{EXPERIMENTAL}

\section{Materials}

The copolymer samples were styrene(S)methyl acrylate (MA) statistical copolymers prepared by radical polymerization in bulk. Table I shows MA-content determined by elemental analysis, apparent molecular weights at the GPC peaks determined by standard polystyrenes and conversions of the samples. Fractions of a low-conversion sample SMA. N-60 (MA: $57.3 \mathrm{~mol} \%$ ) obtained by successive precipitation fractionation ${ }^{23)}$ were also used. Their number average molecular weights determined by osmometry are shown in Table II. Their MA-content was essentially the same in all cases. The eluent for HPLC was a mixture of tetrahydrofuran (THF) and cyclohexane (CHX), both of which were chromatography class reagent of Wako Pure Chemical Industries, Ltd. (Tokyo).

\section{HPLC Instruments}

The instrument of HPLC was HLC-802 of Tosoh Corporation (Tokyo), whose pump was replaced with a high-pressure pump of Type510 of Waters Associates (U.S.A.). The gradient controller was Type-680 of Waters Associates. The UV-detector was ERC-7211 of Erma Inc. (Tokyo). Two columns packed with $\mathrm{CN}$-modified silica gels were used. These were $\mu$-Bondasphere $5 \mu \mathrm{CN}-100 \mathrm{~A}$ and $\mathrm{CN}$ 300A of Waters Associates. The nominal diameters of micropores of gels were $10 \mathrm{~nm}$ for $\mathrm{CN}-100 \mathrm{~A}$ and $30 \mathrm{~nm}$ for $\mathrm{CN}-300 \mathrm{~A}$, respectively. The molecular weights at the exclusion limits determined by standard polystyrenes of Tosoh Corporation in THF at $30^{\circ} \mathrm{C}$ and $1.0 \mathrm{~cm}^{3} \mathrm{~min}^{-1}$ of flow rate, were around $5 \times 10^{4}$ and $3 \times 10^{5}$ for $\mathrm{CN}-100 \mathrm{~A}$ and $\mathrm{CN}$ $300 \mathrm{~A}$, respectively. The length and inner diameter of the columns were $15 \mathrm{~cm}$ and $3.9 \mathrm{~mm}$, respectively.

\section{Experimental Conditions for HPLC}

The temperature of the column bath was $30^{\circ} \mathrm{C}$. The flow rate of the eluent was 1.0
Table I. Copolymer samples

\begin{tabular}{|c|c|c|c|}
\hline \multirow{2}{*}{ Code } & $\mathbf{S}$ & \multirow{2}{*}{$M_{\mathrm{p}} \times 10^{-4 \mathrm{a}}$} & \multirow{2}{*}{$\begin{array}{r}\text { Conv. } \\
w t \%\end{array}$} \\
\hline & $\mathrm{mol} \%$ & & \\
\hline SMA-1 & 23.8 & 6.2 & 22.5 \\
\hline SMA-87-40 & 40.2 & 24 & 9.3 \\
\hline SMA-87-53 & 54.3 & 31 & 10.3 \\
\hline SMA-87-68 & 66.3 & 40 & 8.9 \\
\hline SMA-87-88 & 88.9 & 75 & 2.1 \\
\hline
\end{tabular}

a Values of standard polystrene at the GPC peaks of the samples.

Table II. Fractions of SMA N-60

\begin{tabular}{cc}
\hline Fr. No. & $M_{n} \times 10^{-4 \mathrm{a}}$ \\
\hline 2 & 48.4 \\
6 & 22.3 \\
8 & 9.0 \\
\hline
\end{tabular}

a Osmometry. MA $/ \mathrm{mol}^{\circ} \%$, 57.3.

$\mathrm{cm}^{3} \mathrm{~min}^{-1}$. The polymer concentration of the injected solutions was $0.2 \mathrm{mg} \mathrm{cm}^{-3}$ for each component. That is, the total concentration of 5 components mixture was $1.0 \mathrm{mg} \mathrm{cm}^{-3}$. The injection volume was $0.1 \mathrm{~cm}^{3}$ in all measurements. The wave length of the UV-detector was $259 \mathrm{~nm}$.

The linear gradient of the eluent was used to separate the samples. In all measurements. THF-content was changed from 25 to $65 \mathrm{vol}^{\%} \%$ for $20 \mathrm{~min}$ as shown in Figure 1. The chromatogram of blank elution is also shown in Figure 1, where the base line of the gradient range straight as anticipated from the gradient program.

\section{Determination of Cloud Points}

The samples of different chemical compositions were dissolved in THF at the concentration of $2 \mathrm{mg} \mathrm{cm}^{-3}$, respectively. The first cloud points were determined by titrating the respective solutions with $\mathrm{CHX}$ visually at $30^{\circ} \mathrm{C}$. 


\section{RESULTS}

The chromatograms obtained using the column of $\mathrm{CN}-100 \mathrm{~A}$ for mixtures of 4-components (upper) and 5-components (lower) are shown in Figure 2.

In both cases, the mixtures were clearly separated into the original components according to the order of S-content. The assignments of the respective peaks in Figure 2 were carried out by comparing these chromatograms with those obtained by single compo-


Figure 1. The gradient program used for the Figures $2-4$ and chromatogram of the blank elution by using the column of $\mathrm{CN}-100 \mathrm{~A}$. nent injections. The peak positions for the respective components in the chromatograms obtained by the single component injections were in good agreement with those in the chromatograms of mixtures.

In the chromatogram of 4-components mixture, the peak areas are almost proportional to S-content of the respective components, while in the chromatogram of 5-components mixture, the sample SMA-1 with low molecular weight $\left(6.2 \times 10^{4}\right)$ shows a very small peak area irrespective of the highest S-content.

The chromatograms obtained by the column of $\mathrm{CN}-100 \mathrm{~A}$ for the samples with almost equal MA-content but different molecular weights are shown in Figure 3, where the number average molecular weights and peak areas by an arbitrary unit are illustrated. Two samples with higher molecular weights $\left(2.23 \times 10^{5}\right.$, $4.84 \times 10^{5}$ ) have almost equal peak areas, while the sample of the lowest molecular weight $\left(9 \times 10^{4}\right)$ has a peak area of half those of the other samples.

Figure 4 shows the chromatograms for 5components mixture and the respective components obtained using the column of $\mathrm{CN}$ 300A. The samples with molecular weights of $10^{5}$ order were detected in both chromatograms of the mixture and the single component, respectively, while the sample of SMA-1 with a molecular weight of $10^{4}$ order did not give any peak not only for the mixture but

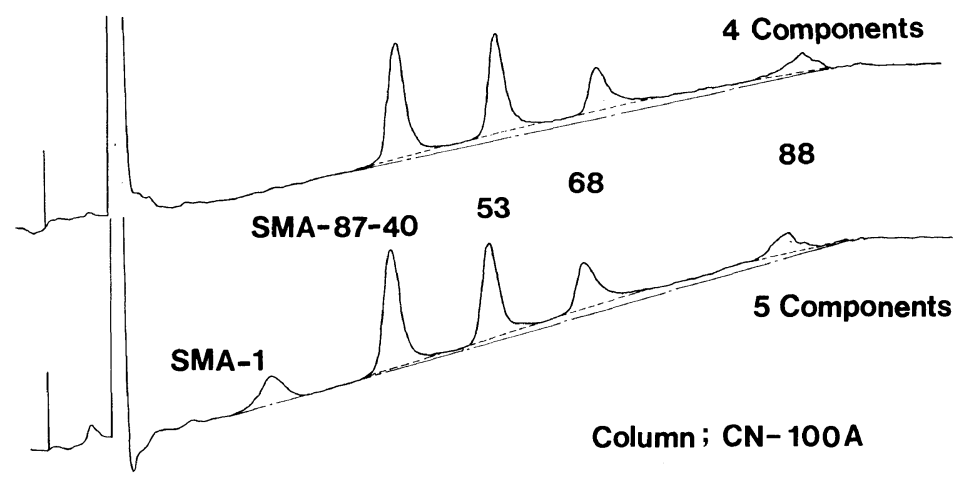

Figure 2. The chromatograms obtained by the column of $\mathrm{CN}-100 \mathrm{~A}$ for mixtures of 4-components and 5-components. 


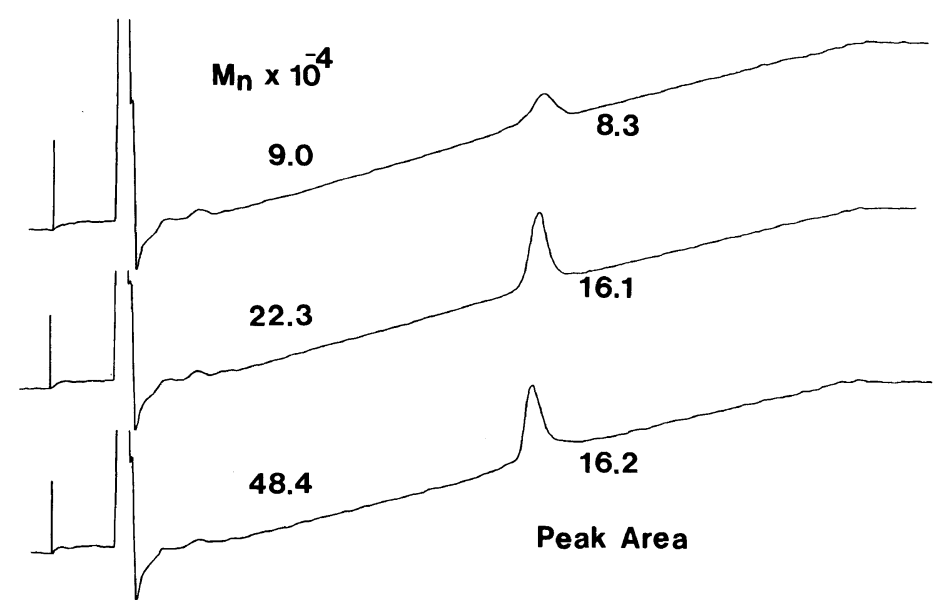

Figure 3. The chromatograms obtained by the $\mathrm{CN}-100 \mathrm{~A}$ column for the fractions of sample $\mathrm{N}-60$ with almost the same MA-content $(57.3 \mathrm{~mol} \%$ ) and different molecular weights (shown in the figure). The peak areas in the figure are expressed in arbitrary units.

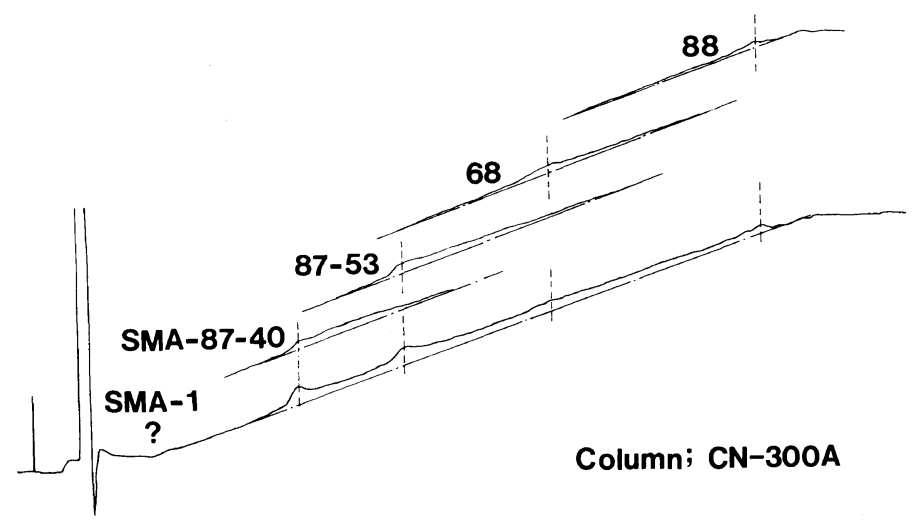

Figure 4. The chromatograms obtained by the column of CN-300A for a mixture of 5-components and for the components separately by single component injections.

also for the single component.

\section{DISCUSSION}

The present copolymer samples were clearly separated into the original components according to their chemical compositions as shown in Figure 2. The content of THF in the eluent at the respective peak positions in the chromatogram obtained by the column of $\mathrm{CN}$ $100 \mathrm{~A}$ was plotted against MA-contents of the samples, together with THF-content at the first cloud points for the samples, in Figure 5. The THF-content at the peak positions by HPLC was higher than those at the first cloud points for the respective samples. This delay of the peak position from the first cloud points may demonstrate that the copolymer components were first dissolved selectively at the first cloud points by a phase-separation mechanism and then the components were separated by an adsorption-desorption mechanism. The elution of each copolymer component may have been determined finally by the 


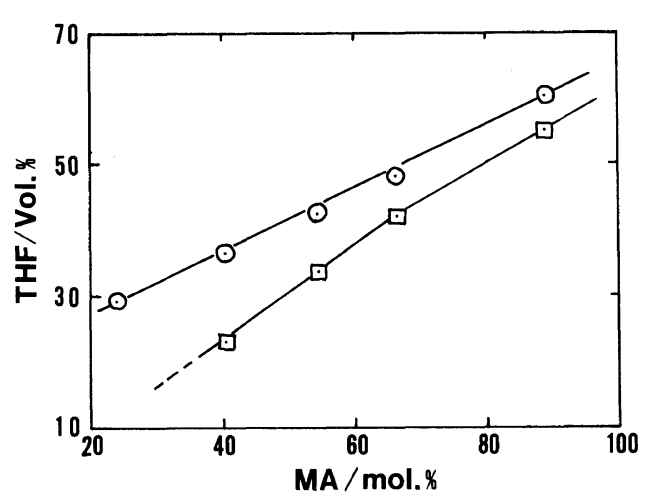

Figure 5. The relationships between MA-content of the copolymer samples and content of THF at the peak positions in the HPLC chromatogram by the column of $\mathrm{CN}-100 \mathrm{~A}$ (Figure 2) and at the first cloud points by titration.

adsorption-desorption mechanism. This may be supported also by the fact that the peak widths in Figure 2 are almost equal to those in Figure 3, though the molecular weight distributions of the samples in Figure 2 are broader than those of the fractions in Figure 3. In this region of molecular weight, the effect of molecular weight cannot be neglected on phaseseparation, but can be neglected on absorption-desoption.

In Figure 2, only the sample SMA-1 with molecular weight of $10^{4}$ order shows an extraordinarily small peak area, while the other samples with molecular weight of $10^{5}$ order gave peak areas proportional to S-content. In Figure 3, only the fraction of No. 8, which has a molecular weight of $10^{4}$ order, shows a peak area half those of the other samples with molecular weights of $10^{5}$ order.

Thus there may exists a gel-permeation effect. The samples of low molecular weight (SMA-1 and Fraction No. 8) contain large amounts of components which can permeate micropores of $10 \mathrm{~nm}$. The components which permeated the micropores may be adsorbed onto the inner surface of the pores, because the polarity of the eluent in the pores is lower than that of the eluent between the gels. Con- sequently, elution of the components with low molecular weight occurs later than that of the components with high molecular weight. Of course, the samples with higher molecular weights also contain low molecular weight components which can permeate the micropores. However, the amounts of those components may be small. The base lines in Figures 2 and 3 are curved upward, whereas the base line of the blank elution in Figure 1 is straight. This must be caused by the components of low molecular weight which can permeate the micropores.

In Figure 4 obtained using the $\mathrm{CN}-300 \mathrm{~A}$ column, all peaks were much lower and broader compared to the peaks in Figure 2 obtained by the column of $\mathrm{CN}-100 \mathrm{~A}$. The peak of SMA-1, very small in Figure 2, has disappeared in Figure 4.

This is also explained by the gel-permeation effect. In the column of $300 \mathrm{~A}$, large amounts of the respective samples can permeate the micropores, so that the gel-permeation mechanism must greatly interfere with compositional fractionation. On the other hand, in the column of $100 \mathrm{~A}$, the components which can permeate the micropores are not so much that interference by the gel-permeation effect is serious.

Consequently, we can say that the present copolymer can be fractionated effectively by HPLC according to chemical composition by co-operative contribution from the mechanisms of adsorption-desorption and phaseseparation. However, if the micropores of the gels in HPLC columns are so large that large amount of the copolymer components can permeate the micropores, the gel-permeation mechanism is unfavorable to compositional fractionation. Therefore, the absorbent gels for compositional fractionation should have micropores that are either large enough for all polymer molecules to permeate, or so small that no polymer molecules can permeate the micropores. 


\section{REFERENCES}

1. H. Inagaki, Adv. Polym. Sci., 24, 190 (1977) and "Thin Layer Chromatography," in "Fractionation of Synthetic Polymers," L. H. Tung, Ed., Marcel Dekker, New York, N. Y., 1977; B. G. Belenkij and E. S. Gankina, J. Chromatogr., 141, 13 (1977).

2. S. Teramachi, A. Hasegawa, Y. Sima, M. Akatsuka, and M. Nakajima, Macromolecules, 12, 992 (1979).

3. G. Riess and P. Callot, "Fractionation of Copolymer," in "Fractionation of Synthetic Polymers," L. H. Tung, Ed., Marcel Dekker, New York, N. Y., 1977.

4. G. Glöckner, H. Kroschwitz, and Ch. Meissner, Acta Polymerica, 33, 614 (1982).

5. M. Danielewicz and M. Kubin, J. Appl. Polym. Sci., 26, 951 (1981).

6. M. Danielewicz, M. Kubin, and S. Vozka, J. Appl. Polym. Sci., 27, 3629 (1982).

7. G. Glöckner, Pure Appl. Chem., 55, 1553 (1983).

8. G. Glöckner and R. Koningsveld, Makromol. Chem., Rapid Commun., 4, 529 (1983).

9. G. Glöckner, Jo H. M. van den Berg, N. L. J. Meijerink, T. G. Scholte, and R. Koningsveld, Macromolecules, 17, 962 (1984).

10. G. Glöckner, Jo H. M. van den Berg, N. L. J. Meijerink, T. G. Scholte, and R. Koningsveld, $J$.
Chromatogr., 317, 615 (1984).

11. H. Sato, H. Takeuchi, S. Suzuki, and Y. Tanaka, Makromol. Chem., Rapid Commun., 5, 719 (1984).

12. G. Glöckner and Jo H. M. van den Berg, Chromatographia, 19, 55 (1984).

13. H. Sato, H. Takeuchi, and Y. Tanaka, Macromolecules, 19, 2613 (1986).

14. S. Mori, Y. Uno, and M. Suzuki, Anal. Chem., 58, 303 (1986).

15. G. Glöckner and Jo H. M. van den Berg, J. Chromatogr., 352, 511 (1986).

16. G. Glöckner and Jo H. M. van den Berg, $J$. Chromatogr., 384, 135 (1987).

17. G. Glöckner, J. Chromatogr., 403, 280 (1987).

18. S. Mori and Y. Uno, J. Appl. Polym. Sci., 34, 2689 (1987).

19. S. Mori and Y. Uno, Anal. Chem., 59, 90 (1987).

20. G. Glöckner, M. Stickler, and W. Wunderlich, Fresenius Z. Anal. Chem., 328, 76 (1987).

21. G. Glöckner, M. Stickler, and W. Wunderlich, Fresenius Z. Anal. Chem., 330, 46 (1988).

22. H. Sato, K. Mitsutani, I. Shimizu, and Y. Tanaka, J. Chromatogr., 447, 387 (1988).

23. S. Teramachi, A. Hasegawa, M. Akatsuka, A. Yamashita, and N. Takemoto, Macromolecules, 11, 1206 (1978). 